\title{
Aerogeophysical characterization of Titan Dome, East Antarctica, and potential as an ice core target
}

\author{
Lucas H. Beem ${ }^{1}$, Duncan A. Young ${ }^{2}$, Jamin S. Greenbaum ${ }^{2}$, Donald D. Blankenship ${ }^{2}$, Marie G. P. Cavitte ${ }^{3}$, \\ Jingxue Guo ${ }^{4}$, and Sun $\mathrm{Bo}^{4}$ \\ ${ }^{1}$ Department of Earth Sciences, Montana State University, Bozeman, MT 59717, USA \\ ${ }^{2}$ Institute for Geophysics, University of Texas at Austin, Austin, TX 78758, USA \\ ${ }^{3}$ Université catholique de Louvain, Earth and Life Institute, Georges Lemaítre Centre for Earth and Climate Research, \\ Place Louis Pasteur, 1348 Louvain-la-Neuve, Belgium \\ ${ }^{4}$ Polar Research Institute of China, Shanghai 200136, China
}

Correspondence: Lucas H. Beem (lucas.beem@montana.edu)

Received: 21 July 2020 - Discussion started: 31 July 2020

Revised: 20 January 2021 - Accepted: 8 February 2021 - Published: 8 April 2021

\begin{abstract}
Based on sparse data, Titan Dome has been identified as having a higher probability of containing ice that would capture the middle Pleistocene transition (1.25 to $0.7 \mathrm{Ma}$ ). New aerogeophysical observations (radar and laser altimetry) collected over Titan Dome, located about $200 \mathrm{~km}$ from the South Pole within the East Antarctic Ice Sheet, were used to characterize the region (e.g., geometry, internal structure, bed reflectivity, and flow history) and assess its suitability as a paleoclimate ice core site. The radar coupled with an available ice core chronology enabled the tracing of dated internal reflecting horizons throughout the region, which also served as constraints on basal ice age modeling. The results of the survey revealed new basal topographic detail and better constrain the ice topographical location of Titan Dome, which differs between community datasets. Titan Dome is not expected to be relevant to the study of the middle Pleistocene transition due to a combination of past fast flow dynamics, the basal ice likely being too young, and the temporal resolution likely being too coarse if $1 \mathrm{Ma}$ ice were to exist.
\end{abstract}

\section{Introduction}

The ice domes and ridges of Antarctica hold the best stratigraphically ordered records of past ice sheet and climate evolution. There is an ongoing international effort (e.g., Fischer et al., 2013; Passalacqua et al., 2018) to find suitable ice core drilling sites that will have an interpretable climate record that spans the middle Pleistocene transition, dated to between 1.25 and 0.7 Ma (Clark et al., 2006). During this period, marine oxygen isotope records indicate a transition in major ice volume and climate cycles from a predominately $\sim 41000$ year obliquity-driven periodicity to a $\sim 100000$-year periodicity. The trapped atmospheric gases and isotopic chemistry of ice cores are proxy records of atmospheric and ice sheet configuration that are key to understanding this transition and climate dynamics more generally.

Identifying coring locations to study the middle Pleistocene transition has primarily been the result of modeling efforts that find regions that have ice dynamic and thermodynamic stability suitable to allow for both $1.5 \mathrm{Ma}$ of ice survival and the existence of a well-preserved ice stratigraphy. One such effort used a one-dimensional thermodynamic model to find where the bed is sufficiently cold to prevent present-day basal melting (Van Liefferinge and Pattyn, 2013). With their model results and the additional criteria of present-day slow flow of less than $2 \mathrm{~m} \mathrm{yr}^{-1}$ and ice thickness greater than $2000 \mathrm{~m}$, they identified regions with increased likelihood for the recovery of an ice core dating to the middle Pleistocene transition (Fig. 1). Follow-on work (Van Liefferinge et al., 2018), used updated methodology and included additional processes, such as parametrization that allows for accumulation rate variability, to refine the boundaries of promising regions. For the regions near Titan Dome (Fig. 1), the boundaries are consistent. 
Not all relevant processes and conditions have been explicitly considered in site determination efforts. Additional considerations that might impact the existence or quality of the desired ice core include past ice flow reorganization and/or ice divide migration (Beem et al., 2017; Winter et al., 2018), subglacial groundwater flow (Gooch et al., 2016), ice surface wind erosion, heterogenous geothermal flux (e.g., Jordan et al., 2018), and minimum age resolution of $\sim 10 \mathrm{kyr} \mathrm{m}^{-1}$ of ice (Fischer et al., 2013). Without geophysical observations, and in some cases direct access, the presence or significance of these processes cannot be determined. Aerial and ground geophysical surveys have occurred for some high-probability coring targets, including at Dome C of East Antarctica (Young et al., 2017). Planning for drilling at Dome $\mathrm{C}$ is proceeding based on the characterization of the region (Young et al., 2017), the existence of a proximal $\sim 800000$-year-old EPICA ice core (Augustin et al., 2004), and promising ice age modeling (Parrenin et al., 2017). However, finding additional targets remains of interest to enable multiple correlatable cores and the examination of spatial heterogeneity in climate processes.

Titan Dome, located approximately $200 \mathrm{~km}$ along the $170^{\circ} \mathrm{W}$ meridian from the South Pole, is a region that was previously identified as a contender for the existence of 1.5-million-year-old ice (Van Liefferinge and Pattyn, 2013; Van Liefferinge et al., 2018). In 2016 and 2017, a partnership between the University of Texas Institute for Geophysics and the Polar Research Institute of China surveyed the South Pole corridor (SPC) grid to evaluate the location as an ice core target. The existence of the South Pole Ice Core chronology (Casey et al., 2014; Winski et al., 2019), plus previously collected aerial-geophysical surveys in the region (Carter et al., 2007), helps propagate the age of internal reflecting horizons (IRHs) throughout the region. The work presented here is part of an expanded mapping of IRH across the Antarctic Ice Sheet (e.g., Winter et al., 2019; Ashmore et al., 2020).

In this paper, we describe new basal topography and surface elevation, determine that the basal ice age is likely younger than would be needed to capture the middle Pleistocene transition, and describe areas on the flanks of Titan Dome that may have previously experienced faster flow than at present.

\section{Data}

\subsection{New data}

The SPC survey was conducted by an aerogeophysical suite installed on the Polar Research Institute of China BT-67 airframe (Cui et al., 2018, 2020) that includes a coherent $60 \mathrm{MHz}$ center frequency radar ice sounder (Peters et al., 2005), a laser altimeter, a cesium magnetometer, a three-axis stabilized gravimeter, and a downward-looking camera. The laser altimeter was a Riegl LD90-3800-HiP and collected data at $4 \mathrm{~Hz}$, with an expected accuracy of $15 \mathrm{~cm}$. Two survey flights were conducted, in February of 2016 and 2017 (Fig. 1), over the area of Titan Dome. A grid of roughly $150 \mathrm{~km}$ by $150 \mathrm{~km}$ with $25 \mathrm{~km}$ grid spacing was surveyed. One survey line was flown within $500 \mathrm{~m}$ of the South Pole Ice Core to enable the propagation of the core's chronology (Winski et al., 2019) throughout the region.

\subsection{Existing data}

One older radar survey of the region is used in this analysis. The Pensacola-Pole Transect (PPT) was collected in 19981999. These data were collected with a radar system that was a direct ancestor of the system used for the SPC survey. The PPT survey used a $60 \mathrm{MHz}$ center frequency with a $250 \mathrm{~ns}$ pulse width radar mounted on a Twin Otter airframe (Carter et al., 2007).

\section{Methods}

\subsection{Radar processing}

The radar data were processed to a 1D focused state (Peters et al., 2007), without range migration. Focusing is applied to differentiate between nadir and off-nadir reflections and improve the resolution of the resulting radargram by increasing the discrimination of internal structures and the basal boundary of the ice sheet.

The calculated basal reflection coefficient has been corrected for geometric spreading loss and for assumed ice attenuation, which is primarily a function of ice temperature (MacGregor et al., 2007; Matsuoka et al., 2012). Geometric spreading loss follows the standard theoretical relation using the infinite mirror approximation (e.g., Lindzey et al., 2020). This study uses an attenuation value of $10 \mathrm{~dB} \mathrm{~km}^{-1}$ everywhere and reported as two-way travel through a given ice thickness. Although attenuation is expected to be variable due to spatial heterogeneity in ice temperature and/or ice chemistry, an attempt to constrain the variability is not made due to the numerous additional processes for which a control would be needed (e.g., subglacial water distribution, geothermal flux heterogeneity, ice chemistry, basal roughness). The relative consistency of low-magnitude basal reflection and the lack of inferred basal water, as will be described later (Sect. 4.2), support the assumptions used in determining the magnitude of the dielectric loss.

To determine the attenuation value, multiple regressions (Fig. 2) with a combination of thickness distribution ( $>800$ and $>1200 \mathrm{~m}$ ) and reflection values in each thickness bin (all, five highest, five lowest) resulted in a range of possible values $\left(6-15 \mathrm{~dB} \mathrm{~km}^{-1}\right)$. Using the highest and lowest values in a bin attempts to isolate the effects of dialectic loss within the ice column by assuming the end-member basal reflection coefficient is consistent throughout the survey. A south polar ice column has an approximate average temperature of 

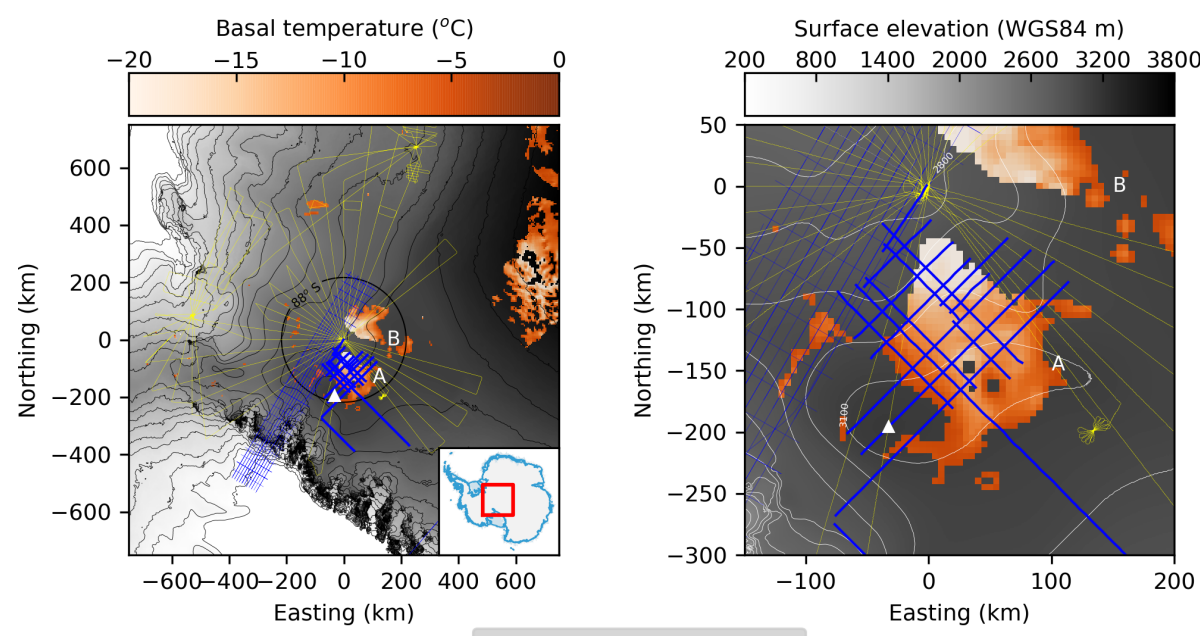

- SPC
PPT

PolarGAP

$\Delta$ Summit

Figure 1. South Pole and Titan Dome region. For both panels, flight lines from the South Pole corridor (SPC) survey and previously published observations of Pensacola-Pole Transect (PPT; Carter et al., 2007) and PolarGAP (Jordan et al., 2018) surveys are also plotted. The orange shading shows candidate regions of increased paleoclimate ice core potential plotted as basal temperature (Van Liefferinge and Pattyn, 2013). Each color bar applies to both panels. The two coring candidate regions discussed in this paper are labeled A and B. The location of Titan Dome summit, as determined from the SPC survey, is the white triangle. The background shading and contours are from the Bamber et al. (2009) surface elevation DEM. The coordinate system used is polar stereographic (EPSG:3031).

$-35^{\circ} \mathrm{C}$ (Beem et al., 2017), and the theoretical values of attenuation for such ice are within $7-15 \mathrm{~dB} \mathrm{~km}^{-1}$, depending on ice chemistry (MacGregor et al., 2007). These values are also in agreement with the results of an ice-sheet-wide estimate of englacial attenuation (Matsuoka et al., 2012). Consistent with theory and observations, $10 \mathrm{~dB} \mathrm{~km}^{-1}$ is used here.

\subsection{Laser altimetry processing}

Laser altimetry was corrected for biases in the attitude of the sensor through minimization of the transect intersection differences (Young et al., 2015) with data from the 2016 survey. As the laser and inertial navigation system was not removed from the aircraft between field seasons, recalibration of the second season was not required.

\subsection{Surface, bed, and internal reflecting horizon tracing}

The manual tracing of the surface and bed within the radar observations was consistent with the methodology described in Blankenship et al. (2001). The human tracers applied a first return criteria to identify the bed. This has the effect of identifying the minimum possible ice thickness and smoothing basal topography, especially in regions with steep and variable relief. Using the traced interfaces along with aircraft position, the surface elevation, bed elevation, and ice thickness are determined. Radar wave speed in ice is assumed to be $1.67 \times 10^{8} \mathrm{~m} \mathrm{~s}^{-1}$.
Internal reflecting horizons were manually traced using Landmark DecisionSpace semi-autonomous picking that uses the maximum value of the reflector. The South Pole Ice Core chronology (Winski et al., 2019) was projected onto the radargram that flew most proximal to the core location $(\sim 500 \mathrm{~m})$, by correlating the ice depth of both the ice core and radar observations. Where IRH are completely continuous the age record was propagated. Internal reflecting horizons may have discontinuities in visibility due to dip steepness, being obscured by radar clutter, the effects or radar processing, or ceasing to generate a suitably strong reflection for other reasons (Siegert, 1999; Harrison, 1973; Holschuh et al., 2014). Nine dated IRHs were traced to their maximum possible extent from the South Pole Ice Core: $0 \mathrm{ka}$ (taken as the surface), 4.7, 10.7, 16.8, 29.1, 37.6, 51.4, 72.5, and 93.9 ka.

The surface, bed, and ice thickness were compared to widely used community datasets (Fretwell et al., 2013; Bamber et al., 2009; Helm et al., 2014) by interpolating the gridded data to each geophysical observation location using a bivariate spline approximation.

\subsection{Basal ice age model}

The age of the basal ice $(a)$ can be modeled with the constraints provided by radar observations and dated IRH. Two 1D models are compared to estimate the age of the basal ice. One model uses the simplest Nye assumptions, which are a steady-state ice thickness $(H)$ and a constant strain rate with depth (Cuffey and Paterson, 2010, Eq. 15.8), 


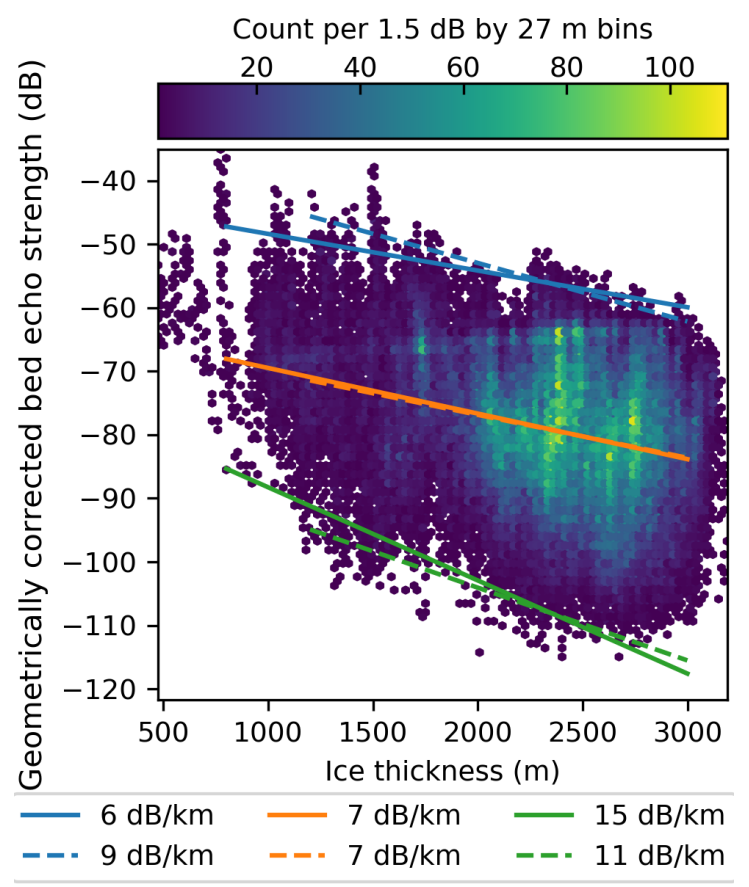

Figure 2. Attenuation determination. The color field represents the number of observations in each $1.5 \mathrm{~dB}$ geometrically corrected echo strength by a $27 \mathrm{~m}$ thickness bin. The solid lines are regressions using observations with ice thickness greater than $800 \mathrm{~m}$ and the dotted lines greater than $1200 \mathrm{~m}$. The orange lines use all observations in each thickness bin. The blue lines use the five highest echo strengths in each thickness bin, and the green line uses the five lowest. The legend reports the regression slope.

$a=\frac{H}{b} \ln \left(\frac{1}{1-z / H}\right)$.

For this model, the one unknown parameter is surface accumulation rate in ice equivalent thickness $(b)$. Basal ice is arbitrarily defined as a depth (z) $30 \mathrm{~m}$ above the bed, and ice thickness $(H)$ is defined by radar observations. The model is run for each vertical radar observation independently by solving for the accumulation rate that minimizes the root mean squared error between the model depth for each IRH age and the traced depth of the IRH. The resulting accumulation field enables an estimate of the spatial patterns of average accumulation rate. Comparing the spatial distribution of accumulation from the model to independent observations/modeling of accumulation (Arthern et al., 2006; Wessem et al., 2014; Studinger et al., 2020) serves as partial model verification.

The second age model uses the Dansgaard-Johnson set of assumptions concerning vertical strain rates (Cuffey and Paterson, 2010, Eqs. 15.14 and 15.15), $a=a^{\prime}+\frac{2 H-h}{b}+\left(\frac{h}{z}-1\right)$,

$a^{\prime}=\frac{2 H-h}{2 b} \ln \left(\frac{2 H-h}{h}\right)$.

A characteristic height $(h)$ above the bed marks the transition from constant vertical strain above to linearly varying to zero below. A range of transitional heights $(h)$ were tested, $20 \%$ to $50 \%$ of ice thickness above the bed. In this model, $z$ is height above bed. The Dansgaard-Johnson model is solved independently for each vertical radar observation by solving for the accumulation $(b)$ that minimizes the root mean squared misfit between the model depth for each IRH age and the traced depth of the IRH. This model is highly sensitive to accumulation rate, which determines the magnitude of vertical strain, but less sensitive to the chosen transitional height. Additionally, the model is sensitive to the definition of basal ice, given the high degree of non-linearity this model produces near the bed. To improve on the arbitrarily defined $30 \mathrm{~m}$ above the bed, a minimum desired temporal resolution of ice, $10 \mathrm{kyr} \mathrm{m}^{-1}$ (Fischer et al., 2013), is used to determine the basal ice age. The basal age output of the model is the age at the depth where this temporal resolution threshold is exceeded.

\subsection{Submergence}

Investigating the submergence rate, the speed that a dated IRH takes to reach its current position, can be informative of the flow history in the region. The submergence rate is calculated with published methodology (Beem et al., 2017) and assuming $m=1$,

$w=-b\left(\frac{z}{H}\right)^{m}$.

The model assumes the form of the vertical strain rate profile and determines the magnitude of vertical strain necessary to submerge an IRH of a given age to its observed depth. Submergence rates $(w)$ are calculated for each dated IRHbounded interval within the ice column. In the above equation, $b$ is ice equivalent surface accumulation, $H$ is ice thickness, and $z$ is height above the bed. There is a correction step that removes the influence of the strain from each younger interval (Beem et al., 2017). Patterns in submergence that exceed expected spatial gradients in accumulation are interpreted to represent heterogenous basal melt or ice flow. The results create a temporal history that can be interpreted as changes to processes that effect submergence rates (e.g., accumulation, basal melt, and/or horizontal strain). 


\section{Results}

\subsection{Bed topography, surface elevation, and ice thickness}

The bed elevation determined by radar reflection reveals a mountainous subglacial terrain that was previously unknown. The bed is rugged, with $>1 \mathrm{~km}$ of relief along the survey lines and bed slopes of up to $45^{\circ}$ (Figs. 3 and 7). The $20 \mathrm{~km}$ line spacing does not resolve the extent of these features, and the effectiveness of mass conservation methods of bed interpolation is limited by low ice velocities (Morlighem et al., 2020), restricting the use of only $1 \mathrm{D}$ modeling approaches. The new observations suggest that the main ice dome is located on a basal topographic high instead of a depression. The ice thickness in this region is therefore commensurately thinner than previously estimated (Fretwell et al., 2013).

There are two independent surface elevation digital elevation models (DEMs) of the Titan Dome region (Bamber et al., 2009; Helm et al., 2014) which other gridded DEM products (e.g., Bedmap2, REMA, BedMachine) use to fill in their data gaps south of $86^{\circ} \mathrm{S}$ (Fretwell et al., 2013; Howat et al., 2019; Morlighem et al., 2020). Generally, there is good agreement between the available DEM products and the new laser altimetry observations of surface elevation (Figs. 3 and 4). The Bamber et al. (2009) DEM is $20 \pm 62 \mathrm{~m}$ (average \pm 2 standard deviations) higher than the SPC radar observations, and the Helm et al. (2014) DEM is $23 \pm 73 \mathrm{~m}$ higher. The Titan Dome summit location differs by at least $34 \mathrm{~km}$ between the Bamber et al. (2009) and Helm et al. (2014) DEMs. The surface altimetry collected here is sparse and cannot explicitly constrain the location of the Titan Dome, but the dome location in the Bamber et al. (2009) DEM was used in survey planning and corresponds to the location of highest elevation observed in this survey. The dome elevation observed by the survey's laser altimetry is $3154 \mathrm{~m}$, within $10 \mathrm{~m}$ elevation of Bamber et al. (2009) data, and occurs at $88.1716^{\circ} \mathrm{S}$, $170.4765^{\circ} \mathrm{W}$, the same position as the Bamber et al. (2009) defined summit.

The bed elevation and ice thickness of the SPC survey compared to the Bedmap2 dataset show significant variance. Bedmap2 is $30 \pm 550 \mathrm{~m}$ (average \pm 2 standard deviations) thicker than the SPC radar observations. A total of $50 \%$ of the radar observations within candidate A (Fig. 1) have thinner ice than Bedmap2 when interpolated from the grid. Given the gridded nature, $69 \%$ of the Bedmap2 pixels within candidate A that were surveyed have thicker ice than the radar observations. The region of the SPC survey only had sparse observations previously available, and differences between the available gridded datasets and the new observations are expected.

\subsection{Basal reflectivity}

The bed beneath Titan Dome and the surrounding region show generally low reflectivity and heterogenous character. Localized regions of higher values $(>-30 \mathrm{~dB})$ are observed in the subglacial drainages that flow towards the FilchnerRonne Ice Shelf (generally grid north or northwest). Higher values are also seen beneath a region of thin ice (Fig. 5 near $0 \mathrm{~km}$ easting and $-50 \mathrm{~km}$ northing).

The low values of basal reflectivity suggest that the basal ice beneath the Titan Dome region is frozen to the bed, and there is limited basal melt and water movement. This conclusion is consistent with previous basal temperature modeling efforts (e.g., Beem et al., 2017; Van Liefferinge et al., 2018; Van Liefferinge and Pattyn, 2013; Price et al., 2002) that conclude the bed in the region is $10^{\circ} \mathrm{C}$ or more below the pressure melting temperature. It is unlikely that bodies of water were detected by radar, but the local reflectivity maximums suggest a higher likelihood of a smoother bed and/or small amounts of basal water in these regions, potentially in the form of saturated sediments or interfacial water. The high reflectivity seen beneath shallow ice may be the result of the attenuation correction that is too large for the cold ice expected there.

\subsection{Basal ice age}

Two models were used to estimate the age of the basal ice, each constrained by radar observations and dated IRH. The Nye age model calculates basal ages as old as $360 \mathrm{ka}$, but much of the region is younger. The modeled accumulation field used to minimize the misfit between dated IRH and modeled ages has a mean accumulation (in ice equivalent) of $4.4 \mathrm{~cm} \mathrm{yr}^{-1}$. The spatial distribution of accumulation has lower magnitudes near the dome summit ( 3 to $5 \mathrm{~cm} \mathrm{yr}^{-1}$ ) and higher rates at lower elevations (up to $9 \mathrm{~cm} \mathrm{yr}^{-1}$ ). This pattern and magnitude is generally consistent with spaceborne and reanalysis estimates of accumulation patterns of the region (Arthern et al., 2006; Wessem et al., 2014). The highest values of accumulation are seen in a region of a broad flat ice surface topographic trough. This matches a recent accumulation study (Studinger et al., 2020) that finds 3 to $5 \mathrm{~cm} \mathrm{yr}^{-1}$ accumulation on the summit and implies higher values of accumulation, up to $20 \mathrm{~cm} \mathrm{yr}^{-1}$, in the ice surface trough. This age model result is not expected to be predictive of modern accumulation rates, and there are deviations from available observations; however, the general patterns are plausibly realistic and lend credence to the model performance despite its simplicity.

The Dansgaard-Johnson age model calculates older ages than the Nye model due to assumptions that lead to smallermagnitude vertical strain rates near the bed. Isolated regions exceeding $1 \mathrm{Ma}$ of age are predicted to exist in the most favorable parameter sets; however, ages between 600 and $800 \mathrm{ka}$ are more typical. The higher the transitional height 

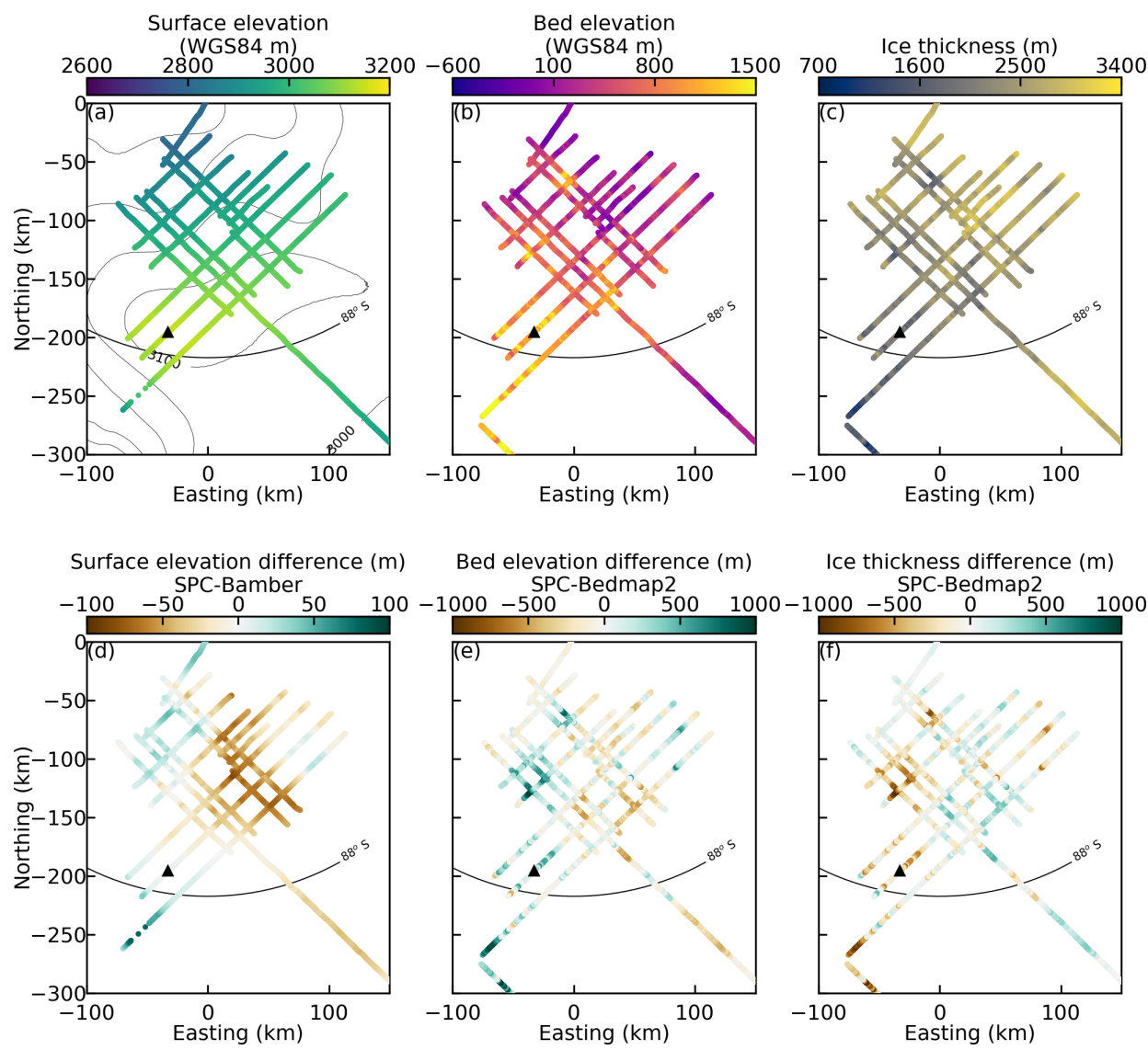

Figure 3. Geophysically observed ice geometry. Panel (a) is laser surface elevation with background $100 \mathrm{~m}$ elevation contours from the Bamber et al. (2009) DEM. (b) Radar-derived bed elevation. (c) Radar-derived ice thickness. (d) Surface elevation difference between the SPC survey and the Bamber et al. (2009) DEM. (e) Bed elevation difference between the SPC survey and Bedmap2 (Fretwell et al., 2013). (f) Ice thickness difference between the SPC survey and Bedmap2 (Fretwell et al., 2013). The dome summit is marked with a black triangle in each panel. The coordinate system used is polar stereographic (EPSG:3031).
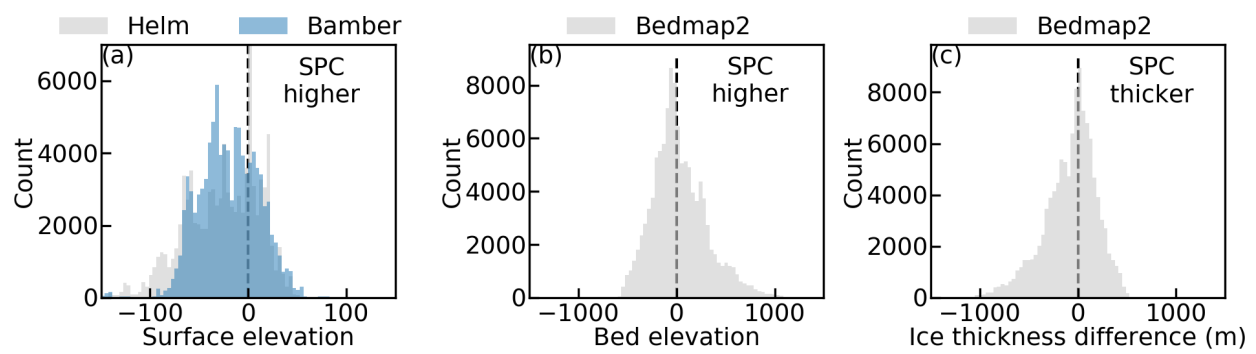

Figure 4. Difference between aerial observations and community DEMs. (a) Laser surface elevation difference for both Bamber et al. (2009) and Helm et al. (2014), (b) radar bed elevation observation difference from Fretwell et al. (2013), and (c) radar ice thickness observation from Fretwell et al. (2013).

in the Dansgaard-Johnson model, the older the maximum basal age due to a greater proportion of the ice thickness with smaller vertical strain rates. With a transitional height (h) at $20 \%$ of ice thickness the maximum age was $\sim 0.9 \mathrm{Ma}$, and when the height is at $50 \%$ of ice thickness the maximum age increased to greater than $1.4 \mathrm{Ma}$. In every model case the probability of suitably old ice to capture the middle Pleistocene transition is low.

The height above the bed of basal ice used by the Dansgaard-Johnson model ranges from 5 to $120 \mathrm{~m}$, due to defining it with a temporal threshold of the model output. When the transitional height $(h)$ is $20 \%$ of ice thickness the mean basal ice is $61 \mathrm{~m}$ above the bed, and when $h$ is $50 \%$ 


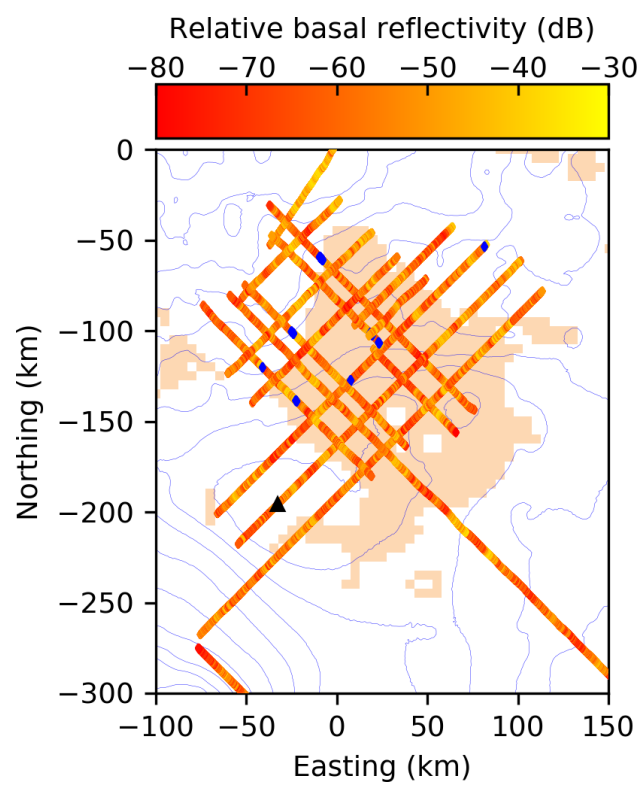

Figure 5. Observed relative basal reflectivity. Reflectivity is corrected for geometric spreading and englacial dielectric attenuation. Locations of reflectivity that exceed $-30 \mathrm{~dB}$ are plotted in blue. The candidate A ice core target region is in orange (Van Liefferinge and Pattyn, 2013). The dome summit location is plotted as a black triangle. The $500 \mathrm{~Pa}$ contour intervals are hydraulic potential using Bedmap2 (Fretwell et al., 2013) and zero effective pressure. The highest contour surrounding the dome summit is $29 \mathrm{kPa}$. The coordinate system used is polar stereographic (EPSG:3031).

the mean basal ice is $79 \mathrm{~m}$ above the bed. Spatial variability in accumulation patterns and magnitudes were consistent with the Nye model results, with less accumulation on the dome $\left(\sim 2 \mathrm{~cm} \mathrm{yr}^{-1}\right)$ and higher amounts on the flanks (up to $\left.10 \mathrm{~cm} \mathrm{yr}^{-1}\right)$.

At an ice divide, the Dansgaard-Johnson model may best be applied with a transitional height that equals ice thickness, resulting in a vertical strain rate that varies linearly from the surface to the bed (Cuffey and Paterson, 2010, p. 619). In this scenario, the basal ages become considerably older, at multiple millions of years. Although such a strain rate profile is only relevant for a small portion of the survey, it creates a hypothetical that if the dome position was highly stable, the local conditions would create a suitable site for the extraction of an ice core that captures the middle Pleistocene transition. However, dome stability over these timescales is generally not expected, particularly for Titan Dome given its proximity to dynamic ice drainages (trans-Antarctic mountain outlet glaciers and Filchner-Ronne ice streams) and evidence that suggest the region has experienced more rapid flow in the past (Sect. 4.4 below; Beem et al., 2017; Lilien et al., 2018; Bingham et al., 2007; Winter et al., 2018).

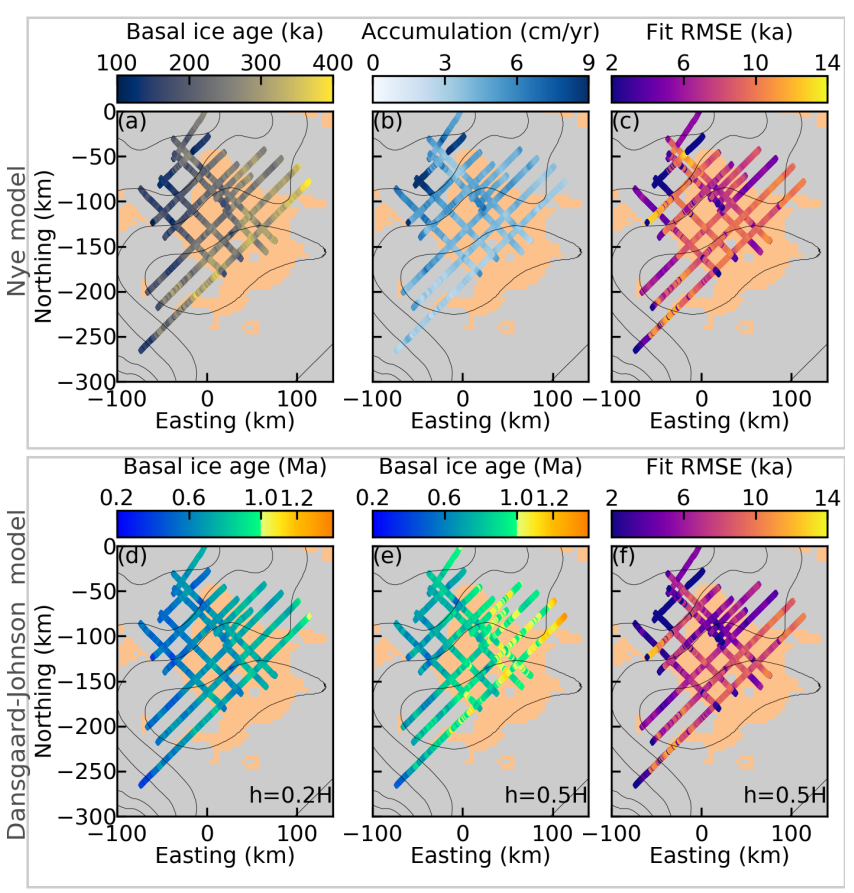

Figure 6. Age model results. The top shows the results of the Nye model and the bottom row the results of the Dansgaard-Johnson model. The RMSE fit is the difference between the model and the dated IRH. Accumulation is reported in ice equivalent units. In panels (d), (e), and (f), "h" is the characteristic height used in the Dansgaard-Johnson model. Each panel is plotted over the candidate A ice core target region in orange (Van Liefferinge and Pattyn, 2013) and $100 \mathrm{~m}$ surface elevation contours (Bamber et al., 2009). The dome is surrounded by the $3100 \mathrm{~m}$ contour. The coordinate system used is polar stereographic (EPSG:3031).

\subsection{Internal reflecting horizon depth and submergence}

Nine dated IRHs were traced to their maximum extent. The younger IRHs were traceable throughout the entire survey region, but older IRHs suffered from discontinuities that prevented tracing. The $72.5 \mathrm{ka}$ IRH was traced throughout a majority of the survey, but it was not possible to trace the $93.9 \mathrm{ka}$ IRH beyond a few tens of kilometers from the ice core location.

The fractional depth of the $72.5 \mathrm{ka}$ IRH ranges from 0.43 to 0.78 with a mean of 0.60 (Figs. 7 and 8). The surveyed dome flanks show the deepest fractional depth for any given IRH. Shallower IRH depths exist nearer the present-day ice divide between Titan Dome and South Pole.

Present-day flow over candidate $\mathrm{A}$ is less than $2 \mathrm{~m} \mathrm{yr}^{-1}$; however, submergence calculations put bounds on the timing of faster ice flow in the past. For the interval starting at the present, 0 to $4.7 \mathrm{ka}$, the submergence gradients (Fig. $8 \mathrm{~b}$ ) are similar to both the magnitude and pattern of presentday accumulation (Arthern et al., 2006; Wessem et al., 2014; Studinger et al., 2020), suggesting that this interval has been dominated by accumulation-driven vertical strain. The 4.7 to 

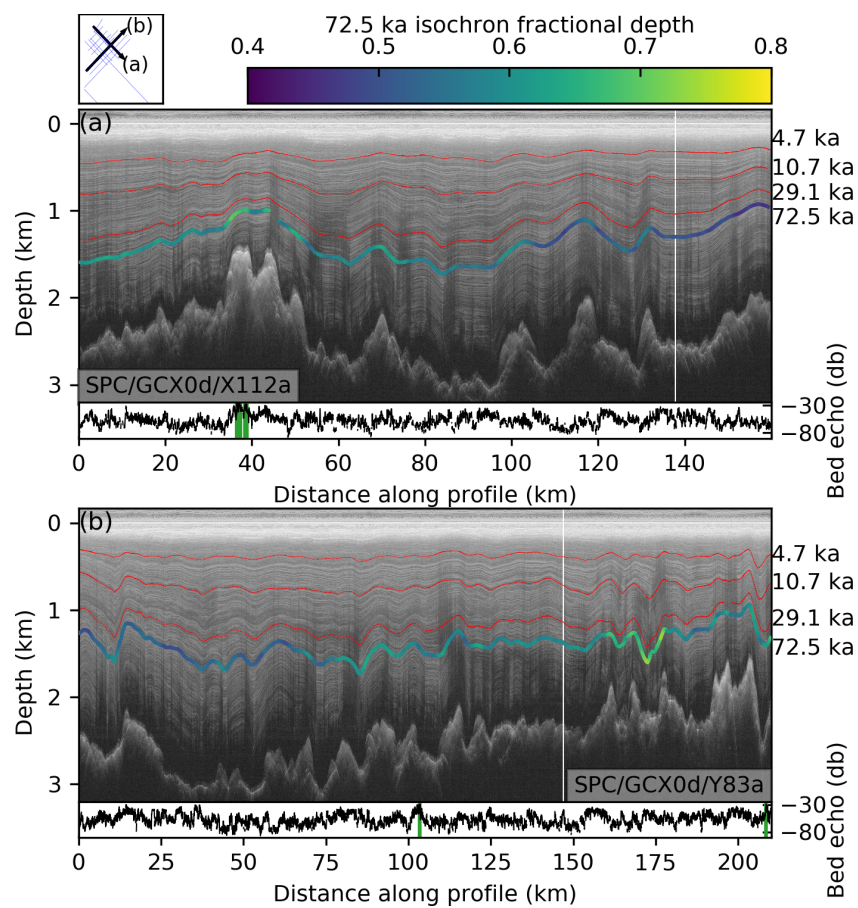

Figure 7. Example radargrams with traced IRH. A context map is in the upper left corner. Beneath each panel is the bed echo strength, which when it exceeds $-30 \mathrm{~dB}$ is highlighted with vertical green lines, the same regions highlighted in Fig. 5. The white vertical line on each radargram represents the intersection of the two transects.

$10.7 \mathrm{ka}$ submergence (not pictured) is very similar to the 0 to $4.7 \mathrm{ka}$ interval. Consistent with the conclusions of Beem et al. (2017), the submergence rates from the interval 10.7 to $16.8 \mathrm{ka}$ (Fig. 8c) show strong, but transitional, submergence boundaries, and the 16.8 to $29.1 \mathrm{ka}$ interval (Fig. 8d) shows high gradient boundaries in submergence. This suggests a region of greater vertical strain ceased during the 10.7 to $16.8 \mathrm{ka}$ interval. The new SPC observations show a contiguous region of greater submergence that is isolated to a single ice catchment. Together this supports the notion that the submergence is caused by ice dynamic processes. Regional geothermal flux anomalies cannot explicitly be excluded. But the region of elevated submergence is bounded by high submergence gradients that are difficult to ascribe solely to accumulation patterns or geothermal flux, suggesting the hypothesis that ice dynamics are driving higher submergence rates.

\section{Discussion}

Titan Dome has been previously identified (Van Liefferinge and Pattyn, 2013; Van Liefferinge et al., 2018) as a region that holds potential for an ice core that would capture the middle Pleistocene transition ( 1.25 to $0.7 \mathrm{Ma})$, due to slow flow, appropriate ice thickness, and the likelihood of basal

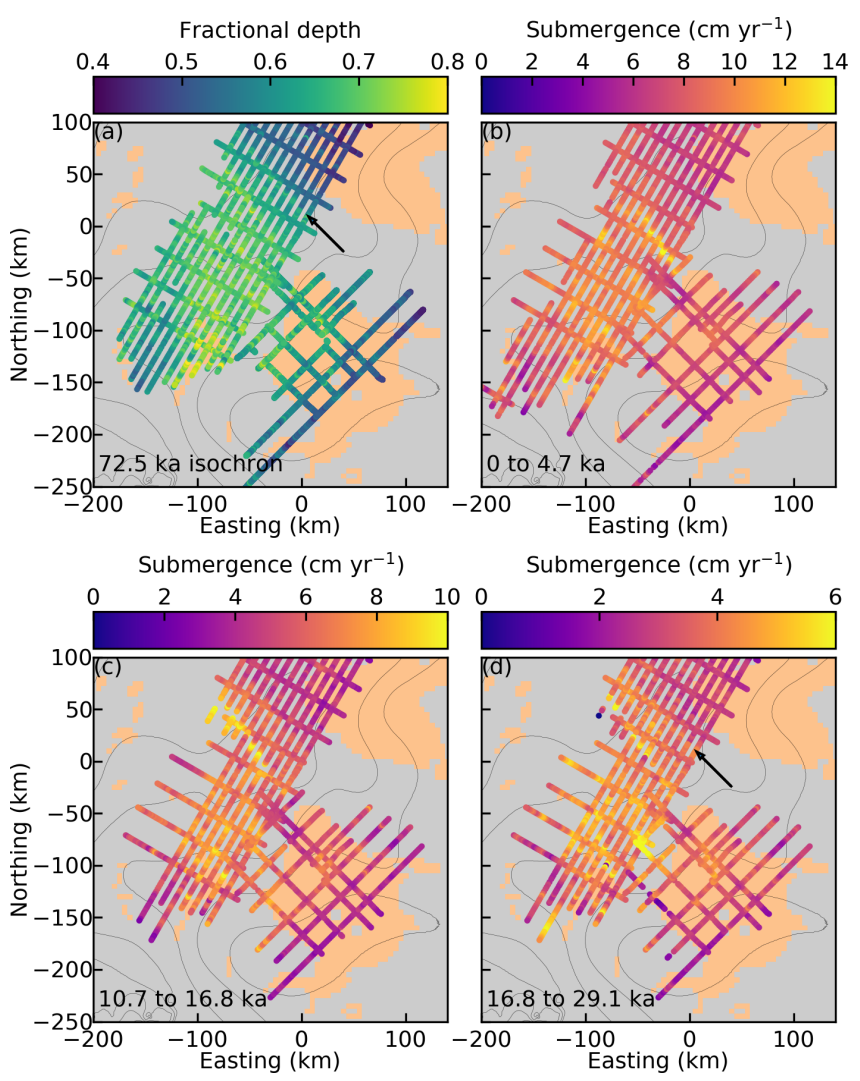

Figure 8. Dated IRH depth and submergence. Panel (a) is the fractional depth of the $72.5 \mathrm{ka}$ IRH. The submergence panels, (b), (c), and (d), show the submergence calculated between two dated IRHs. The black arrow points to and is aligned with a linear feature that marks a boundary of differential IRH drawdown. Each panel is plotted over orange shading, which shows ice core target candidates A and B (Van Liefferinge and Pattyn, 2013), and $100 \mathrm{~m}$ surface elevation contours (Helm et al., 2014). The dome is surrounded by the $3100 \mathrm{~m}$ contour. The coordinate system used is polar stereographic (EPSG:3031).

temperatures that are well below the pressure melting point (Van Liefferinge and Pattyn, 2013; Van Liefferinge et al., 2018; Beem et al., 2017; Price et al., 2002). The analysis completed here shows that the basal ice age is likely too young to be relevant for examination of the middle Pleistocene transition. While much of the Titan Dome region has ice of appropriate thickness, the dated IRH of $72.5 \mathrm{ka}$ is at a significant fractional depth (0.43 to 0.78$)$, decreasing the likelihood of suitably old ice and severely limiting the temporal resolution of old ice if it were to exist (Fig. 8a). In comparison, Little Dome C of East Antarctica has a $72 \mathrm{ka}$ IRH modeled to be between 0.25 and 0.3 of the ice depth (Parrenin et al., 2017).

The age models for Titan Dome fail to calculate ice of suitably old age. The Dansgaard-Johnson model, with assumptions that produce highly non-linear ages approaching the bed, finds only isolated regions of $1.4 \mathrm{Ma}$ in basal ice 
age. Although it is encouraging that the oldest modeled ages are on the dome and flanking ice divides, a typically suitable location for drilling an ice core (Van Liefferinge and Pattyn, 2013; Fischer et al., 2013; Van Liefferinge et al., 2018; Passalacqua et al., 2018), the specific locations with the oldest ages in this study have been previously excluded from consideration due to exceeding the modern ice flow threshold of $2 \mathrm{~m} \mathrm{yr}^{-1}$ (Van Liefferinge and Pattyn, 2013).

The new observations have the effect of reducing the area of suitable regions identified by ice sheet modeling (Van Liefferinge and Pattyn, 2013). The effect of the observed thinner ice, compared to Bedmap2 used to identify candidate A, is twofold and would have competing effects. Thinner ice would tend to increase the area of the region suitable for recovering middle Pleistocene age ice, because fewer locations would exceed their geothermal heat flux threshold for melting. Thinner ice would, however, increase calculated balance velocities excluding more area due to excessive horizontal advection. The candidate A boundary is more ice flow limited than temperature limited, and the net effect of thinner ice would likely be a reduction in the extent of the promising region. For instance, the area between candidates A and B is excluded from Van Liefferinge and Pattyn (2013) because it exceeds their balance velocity threshold of $>2 \mathrm{~m} \mathrm{yr}^{-1}$; also see Bingham et al. (2007).

The flanks of Titan Dome show evidence of increased ice flow in the past, ceasing between 10.7 and $16.8 \mathrm{ka}$. This flow history could result in the loss of basal ice through basal melting and complications in stratigraphic layering due to elevated strain rates. Recent publications have indicated past ice flow on the flanks of Titan Dome is consistent with ice stream transitional flow (Beem et al., 2017; Lilien et al., 2018), which is that between slow ice-deformationdominated flow in the interior ice sheet and basal-slipdominated ice streaming. Given this dynamic history the dome may be prone to divide migration (Winter et al., 2018). Internal reflecting horizon drawdown is consistent with one or more of the following: regional melt from elevated geothermal flux, extensional strain from ice flow, and frictional heating from past ice dynamics. The drawdown pattern includes a linear boundary (see arrow in Fig. 8a) and is completely within a single ice catchment, which supports an ice dynamically induced drawdown. The linear boundary has previously been interpreted as a relic shear margin (Beem et al., 2017). The IRH drawdown (expressed both as elevated submergence and greater IRH depth) seen in the new SPC observations is consistent and contiguous with the pattern from the older PPT observations. The evident ice streaming processes makes this region more complicated for paleoclimate age model construction and the survivability of ice greater than $1 \mathrm{Ma}$.

Candidate B (Fig. 1), a region of modeled cold based ice, along the $\sim 45^{\circ} \mathrm{E}$ meridian from South Pole, does not show enhanced flow history expressed through submergence rates (Beem et al., 2017). Using the same dated IRH, but traced wholly within the older PPT data (Carter et al., 2007), the thickness of ice below the $93.9 \mathrm{ka}$ IRH is generally less than $1200 \mathrm{~m}$ and in some cases considerably less. The fractional depth for the $93.9 \mathrm{ka}$ IRH is 0.60 to 0.70 , for the region with radar observations. If any ice were greater than $1 \mathrm{Ma}$, it is unlikely to have suitable temporal resolution.

The role or existence of elevated geothermal heat flux in the study region is difficult to determine, but there is limited evidence to support its existence. Previous work has suggested a region proximal to Titan Dome has elevated geothermal flux (Jordan et al., 2018), but the basal characterization of Titan Dome neither confirms nor refutes the existence of elevated geothermal flux outside of the SPC survey area. The new survey presented here is of a different subglacial catchment than that identified to host elevated geothermal flux by Jordan et al. (2018), and heterogeneity in geothermal flux is expected over length scales of hundreds of kilometers. The basal reflectivity of Titan Dome does show a few localized areas with a higher likelihood for the existence of water. It is possible that localized geothermal flux could be causing the increased basal reflectivity, which may be in addition to or an alternative hypothesis to remnant heat from past basal sliding (Beem et al., 2017). These hypotheses could be tested through direct access of the bed to characterize the geology and measure geothermal flux.

\section{Conclusions}

Titan Dome is unlikely to be a suitable site for the extraction of an ice core that captures the middle Pleistocene transition. The depth of dated IRH, the age models, and implications for faster flow that ceased during the last glacial maximum are each discouraging to the possibility of suitably old ice. Age models all indicate basal ice age between 300 and $800 \mathrm{ka}$ in the most promising locations. Older modeled ages do occur in some regions when using end-member model parameters. In all instances, the age is younger than the $1.5 \mathrm{Ma}$ ice needed to study the complete middle Pleistocene transition. If $1 \mathrm{Ma}$ or older ice were to exist, IRH ages that are dated and propagated from the South Pole Ice Core (Casey et al., 2014; Winski et al., 2019) would be too deep to have a suitable temporal resolution. Further complication to any extracted ice core from Titan Dome is the evidence for faster flow in the past, which would distort chronology and source regions for any given layer within the core.

The new observations also describe previously unknown basal topography that can be used to further improve community datasets in this region; they have already been added to the BedMachine product (Morlighem et al., 2020). The location of the Titan Dome summit is observed to be consistent with the Bamber et al. (2009) ice surface DEM and located at $88.1716^{\circ} \mathrm{S}, 170.4765^{\circ} \mathrm{W}$ 
Data availability. The L2 data are made available through the USAP data center: https://doi.org/10.15784/601437 (Beem et al., 2021).

Author contributions. This project was made possible by funding acquired by DDB, DAY, JG, and SB and project administration by DAY, DDB, JG, and SB. Conceptualization of the project was completed by LHB, DAY, MPGC, and JSG with investigation by JSG. Formal analysis and visualization was completed by LHB. Methodology was developed by LHB and MGCP. LHB wrote the original draft, and all authors contributed to review and editing. Data curation was completed by DAY and LHB.

Competing interests. The authors declare they have no conflict of interest.

Special issue statement. This article is part of the special issue "Oldest Ice: finding and interpreting climate proxies in ice older than 700000 years (TC/CP/ESSD inter-journal SI)". It is not associated with a conference.

Acknowledgements. The authors would like to thank the Polar Research Institute of China for their support and making their aerial geophysical platform available for this research. The authors also thank Ken Borek Ltd. pilots and engineers for their involvement and support in data collection. The authors thank Mercy Grace Browder and Roccio Castillo for their efforts in radar interpretation and the support of the Jackson School for Geoscience GEOFORCE program. We thank Massimo Frezzotti and Neil Ross for their thoughtful and helpful reviews. This is UTIG contribution no. 3773.

Financial support. This research has been supported by the National Science Foundation, Office of Polar Programs (grant no. 1443690), the G. Unger Vetlesen Foundation, the National Natural Science Foundation of China (grant no. 41876227), and the National Key Research and Development Program of China (grant no. 2018YFB1307504).

Review statement. This paper was edited by Joel Savarino and reviewed by Massimo Frezzotti and Neil Ross.

\section{References}

Arthern, R. J., Winebrenner, D. P., and Vaughan, D. G.: Antarctic snow accumulation mapped using polarization of $4.3 \mathrm{~cm}$ wavelength microwave emission, J. Geophys. Res.-Atmos., 111, D06107, https://doi.org/10.1029/2004JD005667, 2006.

Ashmore, D. W., Bingham, R. G., Ross, N., Siegert, M. J., Jordan, T. A., and Mair, D. W.: Englacial architecture and age-depth constraints across the West Antarctic Ice Sheet, Geophys. Res. Lett.,
47, e2019GL086663, https://doi.org/10.1029/2019GL086663, 2020.

Augustin, L., Barbante, C., Barnes, P. R. F., Marc Barnola, J.,Bigler, M., Castellano, E., Cattani, O., Chappellaz, J., Dahl-Jensen, D., Delmonte, B., Dreyfus, G., Durand, G., Falourd, S.,Fischer, H., Flückiger, J., Hansson, M. E., Huybrechts, P.,Jugie, G., Johnsen, S. J., Jouzel, J., Kaufmann, P., Kipfstuhl, J.,Lambert, F., Lipenkov, V. Y., Littot, G. C., Longinelli, A., Lor-rain, R., Maggi, V., Masson-Delmotte, V., Miller, H., Mul-vaney, R., Oerlemans, J., Oerter, H., Orombelli, G., Parrenin, F.,Peel, D. A., Petit, J.-R., Raynaud, D., Ritz, C., Ruth, U., Schwander, J., Siegenthaler, U., Souchez, R., Stauffer, B., Peder Steffensen, J., Stenni, B., Stocker, T. F., Tabacco, I. E., Udisti, R.,van de Wal, R. S. W., van den Broeke, M., Weiss, J., Wilhelms, F., Winther, J.-G., Wolff, E. W., and Zucchelli, M.: Eight glacial cycles from an Antarctic ice core, Nature, 429, 623-628, https://doi.org/10.1038/nature02599, 2004.

Bamber, J. L., Gomez-Dans, J. L., and Griggs, J. A.: A new 1 km digital elevation model of the Antarctic derived from combined satellite radar and laser data - Part 1: Data and methods, The Cryosphere, 3, 101-111, https://doi.org/10.5194/tc-3-101-2009, 2009.

Beem, L. H., Cavitte, M. G. P., Blankenship, D. D., Carter, S. P., Young, D. A., Moldoon, G., Jackson, C. S., and Siegert, M. J.: Ice-flow reorganization within the East Antarctic Ice Sheet deep 60 interior, in: Exploration of Subsurface Antarctica: Uncovering Past Changes and Modern Processes, edited by: Siegert, M. J., Jamieson, S. R., and White, D. A., Geological Society, London, 461, 35-47, https://doi.org/10.1144/SP461.14, 2017.

Beem, L. H., Young, D. A., Greenbaum, J., Ng, G., Blankenship, D. D., Cavitte, M. G. P., Jingxue, G., and Bo, S.: Titan Dome, East Antarctica, Aerogephysical Survey, U.S. Antarctic Program (USAP) Data Center, https://doi.org/10.15784/601437, 2021.

Bingham, R. G., Siegert, M. J., Young, D. A., and Blankenship, D. D.: Organized flow from the South Pole to the Filchner-Ronne ice shelf: An assessment of balance velocities in interior East Antarctica using radio echo sounding data, J. Geophys. Res.Earth, 112, F03S26, https://doi.org/10.1029/2006JF000556, 2007.

Blankenship, D., Morse, D., Finn, C., Bell, R., Peters, M., Kempf, S., Hodge, S., Studinger, M., Behrendt, J. C., and Brozena, J.: Geologic controls on the initiation of rapid basal motion for West Antarctic ice streams: A geophysical perspective including new airborne radar sounding and laser altimetry results, in: The West Antarctic Ice Sheet: Behavior and Environment, edited by: Alley, R. B. and Bindschadler, R. A., American Geophysical Union, Washington, D.C., 105-121, https://doi.org/10.1029/AR077p0105, 2001.

Carter, S. P., Blankenship, D. D., Peters, M. E., Young, D. A., Holt, J. W., and Morse, D. L.: Radar-based subglacial lake classification in Antarctica, Geochem. Geophy. Geosy., 8, Q03016, https://doi.org/10.1029/2006GC001408, 2007.

Casey, K. A., Fudge, T. J., Neumann, T., Steig, E. J., Cavitte, M., and Blankenship, D. D.: The $1500 \mathrm{~m}$ South Pole ice core: recovering a 40 ka environmental record, Ann. Glaciol., 55, 137-146, https://doi.org/10.3189/2014AoG68A016, 2014.

Clark, P. U., Archer, D., Pollard, D., Blum, J. D., Rial, J. A., Brovkin, V., Mix, A. C., Pisias, N. G., and Roy, M.: The middle Pleistocene transition: characteristics, mech- 
anisms, and implications for long-term changes in atmospheric $\mathrm{pCO}_{2}$, Quaternary Sci. Rev., 25, 3150-3184, https://doi.org/10.1016/j.quascirev.2006.07.008, 2006.

Cuffey, K. M. and Paterson, W. S. B.: The Physics of Glaciers, 4th Edn., Butterworth-Heinemann, Burlington, MA, p. 693, 2010.

Cui, X., Greenbaum, J. S., Beem, L. H., Guo, J., Ng, G., Li, L., Blankenship, D., and Sun, B.: The First Fixed-wing Aircraft for Chinese Antarctic Expeditions: Airframe, modifications, Scientific Instrumentation and Applications, J. Environ. Eng. Geoph., 23, 1-13, https://doi.org/10.2113/JEEG23.1.1, 2018.

Cui, X., Greenbaum, J. S., Lang, S., Zhao, X., Li, L., Guo, J., and Sun, B.: The Scientific Operations of Snow Eagle 601 in Antarctica in the Past Five Austral Seasons, Remote Sens.-Basel, 12, 2994, https://doi.org/10.3390/rs12182994, 2020.

Fischer, H., Severinghaus, J., Brook, E., Wolff, E., Albert, M., Alemany, O., Arthern, R., Bentley, C., Blankenship, D., Chappellaz, J., Creyts, T., Dahl-Jensen, D., Dinn, M., Frezzotti, M., Fujita, S., Gallee, H., Hindmarsh, R., Hudspeth, D., Jugie, G., Kawamura, K., Lipenkov, V., Miller, H., Mulvaney, R., Parrenin, F., Pattyn, F., Ritz, C., Schwander, J., Steinhage, D., van Ommen, T., and Wilhelms, F.: Where to find 1.5 million year old ice for the IPICS "Oldest-Ice" ice core, Clim. Past, 9, 2489-2505, https://doi.org/10.5194/cp-9-2489-2013, 2013.

Fretwell, P., Pritchard, H. D., Vaughan, D. G., Bamber, J. L., Barrand, N. E., Bell, R., Bianchi, C., Bingham, R. G., Blankenship, D. D., Casassa, G., Catania, G., Callens, D., Conway, H., Cook, A. J., Corr, H. F. J., Damaske, D., Damm, V., Ferraccioli, F., Forsberg, R., Fujita, S., Gim, Y., Gogineni, P., Griggs, J. A., Hindmarsh, R. C. A., Holmlund, P., Holt, J. W., Jacobel, R. W., Jenkins, A., Jokat, W., Jordan, T., King, E. C., Kohler, J., Krabill, W., Riger-Kusk, M., Langley, K. A., Leitchenkov, G., Leuschen, C., Luyendyk, B. P., Matsuoka, K., Mouginot, J., Nitsche, F. O., Nogi, Y., Nost, O. A., Popov, S. V., Rignot, E., Rippin, D. M., Rivera, A., Roberts, J., Ross, N., Siegert, M. J., Smith, A. M., Steinhage, D., Studinger, M., Sun, B., Tinto, B. K., Welch, B. C., Wilson, D., Young, D. A., Xiangbin, C., and Zirizzotti, A.: Bedmap2: improved ice bed, surface and thickness datasets for Antarctica, The Cryosphere, 7, 375-393, https://doi.org/10.5194/tc-7-375-2013, 2013.

Gooch, B. T., Young, D. A., and Blankenship, D. D.: Potential groundwater and heterogeneous heat source contributions to ice sheet dynamics in critical submarine basins of East Antarctica, Geochem. Geophy. Geosy., 17, 395-409, https://doi.org/10.1002/2015GC006117, 2016.

Harrison, C. H.: Radio echo sounding of horizontal layers in ice, J. Glaciol., 12, 383-397, https://doi.org/10.3189/S0022143000031804, 1973.

Helm, V., Humbert, A., and Miller, H.: Elevation and elevation change of Greenland and Antarctica derived from CryoSat2, The Cryosphere, 8, 1539-1559, https://doi.org/10.5194/tc-81539-2014, 2014.

Holschuh, N., Christianson, K., and Anandakrishnan, S.: Power loss in dipping internal reflectors, imaged using ice-penetrating radar, Ann. Glaciol., 55, 49-56, https://doi.org/10.3189/2014AoG67A005, 2014.

Howat, I. M., Porter, C., Smith, B. E., Noh, M.-J., and Morin, P.: The Reference Elevation Model of Antarctica, The Cryosphere, 13, 665-674, https://doi.org/10.5194/tc-13-665-2019, 2019.
Jordan, T., Martin, C., Ferraccioli, F., Matsuoka, K., Corr, H., Forsberg, R., Olesen, A., and Siegert, M.: Anomalously high geothermal flux near the South Pole, Sci. Rep.-UK, 8, 16785, https://doi.org/10.1038/s41598-018-35182-0, 2018.

Lilien, D. A., Fudge, T., Koutnik, M. R., Conway, H., Osterberg, E. C., Ferris, D. G., Waddington, E. D., and Stevens, C. M.: Holocene Ice-Flow Speedup in the Vicinity of the South Pole, Geophys. Res. Lett., 45, 6557-6565, https://doi.org/10.1029/2018GL078253, 2018.

Lindzey, L. E., Beem, L. H., Young, D. A., Quartini, E., Blankenship, D. D., Lee, C.-K., Lee, W. S., Lee, J. I., and Lee, J.: Aerogeophysical characterization of an active subglacial lake system in the David Glacier catchment, Antarctica, The Cryosphere, 14, 2217-2233, https://doi.org/10.5194/tc-14-2217-2020, 2020.

MacGregor, J. A., Winebrenner, D. P., Conway, H. B., Matsuoka, K., Mayewski, P. A., and Clow, G. D.: Modeling englacial radar attenuation at Siple Dome, West Antarctica, using ice chemistry and temperature data, J. Geophys. Res.-Earth, 112, F03008, https://doi.org/10.1029/2006JF000717, 2007.

Matsuoka, K., MacGregor, J. A., and Pattyn, F.: Predicting radar attenuation within the Antarctic ice sheet, Earth Planet. Sc. Lett., 359, 173-183, https://doi.org/10.1016/j.epsl.2012.10.018, 2012.

Morlighem, M., Rignot, E., Binder, T., Blankenship, D., Drews, R., Eagles, G., Eisen, O., Ferraccioli, F., Forsberg, R., Fretwell, P., Goel, V., Greenbaum, J. S., Gudmundsson, H., Guo, J., Helm, V., Hofstede, C., Howat, I., Humbert, A., Jokat, W., Karlsson, N. B., Lee, W. S., Matsuoka, K., Millan, R., Mouginot, J., Paden, J., Pattyn, F., Roberts, J., Rosier, S., Ruppel, A., Seroussi, H., Smith, E. C., Steinhage, D., Sun, B., Broeke, M. R. V. D., Ommen, T. D. V., Wessem, M. V., and Young, D. A.: Deep glacial troughs and stabilizing ridges unveiled beneath the margins of the Antarctic ice sheet, Nat. Geosci., 13, 132-137, https://doi.org/10.1038/s41561-019-0510-8, 2020.

Parrenin, F., Cavitte, M. G. P., Blankenship, D. D., Chappellaz, J., Fischer, H., Gagliardini, O., Masson-Delmotte, V., Passalacqua, O., Ritz, C., Roberts, J., Siegert, M. J., and Young, D. A.: Is there 1.5-million-year-old ice near Dome C, Antarctica?, The Cryosphere, 11, 2427-2437, https://doi.org/10.5194/tc-11-24272017, 2017.

Passalacqua, O., Cavitte, M., Gagliardini, O., Gillet-Chaulet, F., Parrenin, F., Ritz, C., and Young, D.: Brief communication: Candidate sites of $1.5 \mathrm{Myr}$ old ice $37 \mathrm{~km}$ southwest of the Dome C summit, East Antarctica, The Cryosphere, 12, 2167-2174, https://doi.org/10.5194/tc-12-2167-2018, 2018

Peters, M. E., Blankenship, D. D., and Morse, D. L.: Analysis techniques for coherent airborne radar sounding: Application to West Antarctic ice streams, J. Geophys. Res.-Sol. Ea., 110, B06303, https://doi.org/10.1029/2004JB003222, 2005.

Peters, M. E., Blankenship, D. D., Carter, S. P., Kempf, S. D., Young, D. A., and Holt, J. W.: Along-track focusing of airborne radar sounding data from West Antarctica for improving basal reflection analysis and layer detection, IEEE T. Geosci. Remote, 45, 2725-2736, https://doi.org/10.1109/TGRS.2007.897416, 2007.

Price, P. B., Nagornov, O. V., Bay, R., Chirkin, D., He, Y., Miocinovic, P., Richards, A., Woschnagg, K., Koci, B., and Zagorodnov, V.: Temperature profile for glacial ice at the South Pole: Implications for life in a nearby subglacial lake, P. Natl. Acad. Sci. 
USA, 99, 7844-7847, https://doi.org/10.1073/pnas.082238999, 2002.

Siegert, M. J.: On the origin, nature and uses of Antarctic icesheet radio-echo layering, Prog. Phys. Geog., 23, 159-179, https://doi.org/10.1177/030913339902300201, 1999.

Studinger, M., Medley, B. C., Brunt, K. M., Casey, K. A., Kurtz, N. T., Manizade, S. S., Neumann, T. A., and Overly, T. B.: Temporal and spatial variability in surface roughness and accumulation rate around $88^{\circ} \mathrm{S}$ from repeat airborne geophysical surveys, The Cryosphere, 14, 3287-3308, https://doi.org/10.5194/tc-14-32872020, 2020.

Van Liefferinge, B. and Pattyn, F.: Using ice-flow models to evaluate potential sites of million year-old ice in Antarctica, Clim. Past, 9, 2335-2345, https://doi.org/10.5194/cp-9-23352013, 2013.

Van Liefferinge, B., Pattyn, F., Cavitte, M. G. P., Karlsson, N. B., Young, D. A., Sutter, J., and Eisen, O.: Promising Oldest Ice sites in East Antarctica based on thermodynamical modelling, The Cryosphere, 12, 2773-2787, https://doi.org/10.5194/tc-122773-2018, 2018.

Wessem, J. M. V., Reijmer, C. H., Morlighem, M., Mouginot, J., Rignot, E., Medley, B., Joughin, I., Wouters, B., DePoorter, M. A., Bamber, J. L., Lenaerts, J. T. M., van de Berg, W. J., van den Broeke, M. R., and van Meijgaard, E.: Improved representation of East Antarctic surface mass balance in a regional atmospheric climate model, J. Glaciol., 60, 761-770, https://doi.org/10.3189/2014JoG14J051, 2014.

Winski, D. A., Fudge, T. J., Ferris, D. G., Osterberg, E. C., Fegyveresi, J. M., Cole-Dai, J., Thundercloud, Z., Cox, T. S., Kreutz, K. J., Ortman, N., Buizert, C., Epifanio, J., Brook, E. J., Beaudette, R., Severinghaus, J., Sowers, T., Steig, E. J., Kahle, E. C., Jones, T. R., Morris, V., Aydin, M., Nicewonger, M. R., Casey, K. A., Alley, R. B., Waddington, E. D., Iverson, N. A., Dunbar, N. W., Bay, R. C., Souney, J. M., Sigl, M., and McConnell, J. R.: The SP19 chronology for the South Pole Ice Core - Part 1: volcanic matching and annual layer counting, Clim. Past, 15, 1793-1808, https://doi.org/10.5194/cp-15-1793-2019, 2019.
Winter, A., Steinhage, D., Creyts, T. T., Kleiner, T., and Eisen, O.: Age stratigraphy in the East Antarctic Ice Sheet inferred from radio-echo sounding horizons, Earth Syst. Sci. Data, 11, 10691081, https://doi.org/10.5194/essd-11-1069-2019, 2019.

Winter, K., Ross, N., Ferraccioli, F., Jordan, T. A., Corr, H. F., Forsberg, R., Matsuoka, K., Olesen, A. V., and Casal, T. G.: Topographic steering of enhanced ice flow at the bottleneck between East and West Antarctica, Geophys. Res. Lett., 45, 4899-4907, https://doi.org/10.1029/2018GL077504, 2018.

Young, D. A., Lindzey, L. E., Blankenship, D. D., Greenbaum, J. S., de Gorord, A. G., Kempf, S. D., Roberts, J. L., Warner, R. C., Van Ommen, T., Siegert, M. J., and Le Meur, E.: Land-ice elevation changes from photon-counting swath altimetry: first applications over the Antarctic ice sheet, J. Glaciol., 61, 17-28, https://doi.org/10.3189/2015JoG14J048, 2015.

Young, D. A., Roberts, J. L., Ritz, C., Frezzotti, M., Quartini, E., Cavitte, M. G. P., Tozer, C. R., Steinhage, D., Urbini, S., Corr, H. F. J., van Ommen, T., and Blankenship, D. D.: High-resolution boundary conditions of an old ice target near Dome C, Antarctica, The Cryosphere, 11, 1897-1911, https://doi.org/10.5194/tc11-1897-2017, 2017. 